\title{
Effects of supraphysiological concentrations of progesterone on the characteristics of the oestradiol- induced gonadotrophin surge in women
}

\author{
I. E. Messinis and A. A. Templeton \\ Department of Obstetrics and Gynaecology, University of Aberdeen, Foresterhill, \\ Aberdeen $A B 92 Z D, U K$
}

\begin{abstract}
Summary. Intramuscular injections of oestradiol benzoate were given to 8 normally cyclic women in the early follicular phase of 3 different cycles. Progesterone was also injected in the second (low dose) and the third cycle (high dose). Oestradiol induced simultaneous surges of $\mathrm{LH}$ and FSH in all women and the onset of these surges was advanced by progesterone. Low-dose progesterone induced a significant increase in the amplitude and the duration of the LH and FSH surges, while high-dose progesterone decreased the duration significantly. In contrast to the oestrogen-only treatment cycles, when the women were treated with progesterone, basal LH and FSH concentrations were suppressed significantly not only before the onset but also after the end of the surge. The results suggest that progesterone affects the dimension of the oestradiolinduced gonadotrophin surge by exerting both a stimulatory and an inhibitory effect on pituitary gonadotrophin secretion. Supraphysiological concentrations of progesterone decreased the duration of the oestradiol-induced gonadotrophin surge significantly and this is possibly part of the mechanism which attenuates the endogenous LH surge in women superovulated for in-vitro fertilization.
\end{abstract}

Keywords: LH surge; gonadotrophins; progesterone; oestradiol; man

\section{Introduction}

It has been established that the midcycle $\mathrm{LH}$ surge is the result of the positive feedback effect of oestradiol on the hypothalamic-pituitary system (Yen \& Lein, 1976). Several studies have shown the ability of exogenous oestrogen with or without progesterone to induce an LH surge in cyclic and post-menopausal women (Tsai \& Yen, 1971; Yen \& Tsai, 1972; Leyendecker et al., 1972; Chang \& Jaffe, 1978; March et al., 1979). Although the role of progesterone in timing the endogenous LH surge in spontaneous cycles is not clear (Hoff et al., 1983; Liu et al., 1987), the augmenting effect of preovulatory progesterone concentrations on the oestradiol-induced $\mathrm{LH}$ surge has been established (Liu \& Yen, 1983). However, data on the relationship between the actual concentrations of progesterone in blood during the $\mathrm{LH}$ surge and the characteristics of the surge are very limited (Leyendecker et al., 1972; Chang \& Jaffe, 1978).

In women undergoing multiple follicular development for in-vitro fertilization the endogenous LH surge is markedly attenuated both in amplitude and duration (Messinis et al., 1985; Messinis \& Templeton, 1986). In these cycles, serum progesterone concentrations during the LH surge are in general supraphysiological although they can be as low as those in spontaneous cycles (Messinis et al. 1985; Messinis \& Templeton, 1986). Although it seems that a non-steroidal gonadotrophin surge-attenuating factor (GnSAF) is secreted by the hyperstimulated ovaries (Messinis et al., 1986; Messinis \& Templeton, 1989), the effect of high progesterone concentrations on the characteristics of the LH surge has not been previously investigated. 


\section{Materials and Methods}

Patients. Eight normally ovulating women volunteered for the study and gave written informed consent. This study was approved by the local ethical committee. Three experiments were performed in each woman during the early follicular phase of 3 consecutive cycles. The early follicular phase was chosen because at that stage of the cycle endogenous production of ovarian steroids is minimal. In each of the 3 cycles the women were given a total of 6 intramuscular injections of oestradiol benzoate (Benztrone ampoules; Paines and Byrne Ltd, Greenford, Middlesex, UK) every $12 \mathrm{~h}$ starting on cycle Day $2(09: 00 \mathrm{~h})$. The dose of oestradiol benzoate in each injection was 200, 250, 500, 500,500 and $500 \mu \mathrm{g}$ respectively. The purpose was to induce serum oestradiol concentrations similar to those seen during the preovulatory period of spontaneous cycles (Messinis \& Templeton, 1988a).

During the 2 nd and the 3 rd cycle, the last injection of oestradiol benzoate was combined with an intramuscular injection of $1.5 \mathrm{mg}$ progesterone (Gestone ampoules; Paines and Byrne Ltd). Then, the women were given another 5 intramuscular injections of progesterone every $12 \mathrm{~h}$ at the following doses: during the 2 nd cycle 1.5, 1.5, 1.75, 2.0 and $3.0 \mathrm{mg}$ respectively (low-dose progesterone) and during the $3 \mathrm{rd}$ cycle $5 \cdot 0,5 \cdot 0,5 \cdot 0,7.5$ and $7.5 \mathrm{mg}$ respectively (high-dose progesterone). The intention was to induce serum progesterone concentrations in the 2 nd cycle similar to those during the LH surge of spontaneous cycles (Messinis \& Templeton, 1987) and in the 3rd cycle similar to those during the LH surge of superovulated cycles (Messinis et al., 1985). Information regarding the doses of oestradiol benzoate and progesterone was obtained from pilot experiments performed in 2 volunteer post-menopausal women. The total number of experiments performed in the 8 women was 23 . One womar had only 2 experiments ( 1 st and 2 nd cycle).

Blood samples were taken from each woman initially every $12 \mathrm{~h}$, i.e. before each oestradiol injection, and every $6 \mathrm{~h}$ thereafter for $72 \mathrm{~h}$. In all blood samples, concentrations of FSH, LH, oestradiol and progesterone were measured.

Hormone assays. Measurement of FSH in serum was done by a immunoradiometric assay incorporating two highaffinity monoclonal antibodies. Kits were purchased from Serono Diagnostics Ltd, Woking, Surrey, UK (FSH, MAIA Clone). They contain fluorescein-labelled and ${ }^{125}$ I-labelled mouse monoclonal antibodies to FSH. The crossreaction with other glycoprotein hormones is $<0.2 \%$. The results are expressed as mi.u. $/ \mathrm{ml}$ of standards calibrated against the WHO 2nd IRP of human FSH (78/549). Measurement of LH in serum was done by a similar immunoradiometric assay with two high-affinity monoclonal antibodies using kits purchased from Serono Diagnostics Ltd (LH MAIA clone). They contain fluorescein-labelled and ${ }^{125}$ I-labelled mouse monoclonal antibodies to LH. The cross-reaction with other glycoprotein hormone is $<1 \%$. The results are expressed as mi.u. $/ \mathrm{ml}$ of standards calibrated against the WHO Ist IRP for human LH (68/40). The use of high-affinity monoclonal antibodies to FSH and LH offers an increased level of sensitivity and specificity compared with traditional methods (Soos \& Siddle, 1983; Rattle et al., 1984). Oestradiol-17 $\beta$ was measured in serum by a direct radioimmunoassay using a kit purchased from Biodata (Serono Diagnostics Ltd). The anti-oestradiol antibody was raised in rabbit against oestradiol-17 $\beta$. The cross-reaction with other steroidal compounds is $<1 \%$. Values are expressed as pmol/1. Progesterone was measured in serum using the Amerlex-M Progesterone RIA kit (Amersham International plc, Amersham, Bucks, UK) and results are expressed as $\mathrm{nmol} / \mathrm{l}$. The cross-reaction with other steroids is $<1 \%$. The lower limits of detection of the FSH, $\mathrm{LH}$, oestradiol and progesterone assays were $0.25 \mathrm{mi} . \mathrm{u} . / \mathrm{ml}, 0.15 \mathrm{mi} . \mathrm{u} . / \mathrm{ml}, 55 \mathrm{pmol} / 1$ and $0.25 \mathrm{nmol} / \mathrm{l}$, respectively, while interassay and intra-assay coefficients of variation were 5.2 and $3.5 \%, 12 \cdot 5$ and $10.0 \%, 8.0$ and $5.0 \%$ and $9 \cdot 4$ and $5 \cdot 1 \%$ respectively.

Statistical analysis. The results are given as mean \pm s.e.m. and were statistically analysed using one-way analysis of variance. The hormone values were transformed into logarithms in the statistical calculations.

\section{Results}

Figure 1 shows serum oestradiol, FSH and LH concentrations during the administration of oestradiol benzoate in the 1st cycle. A marked increase in serum oestradiol values was achieved in all women (from $90 \pm 13$ to $1365 \pm 154 \mathrm{pmol} / \mathrm{l}$ at $60 \mathrm{~h}, P<0.001$ ), which resulted in a significant decrease in serum basal concentrations of both $\mathrm{LH}$ (from $3.7 \pm 0.7$ to $1.1 \pm 0.3 \mathrm{mi} . \mathrm{u}$. $/ \mathrm{ml}$, $P<0.001$ ), and FSH (from $8.3 \pm 0.8$ to $3.4 \pm 0.2 \mathrm{mi} . \mathrm{u} . / \mathrm{ml}, P<0.001$ ). Although LH concentrations decreased more rapidly than FSH values during the first $12 \mathrm{~h}$ of treatment the percentage decrease for these two hormones was similar at $48 \mathrm{~h}(35.0 \pm 10.8 \%$ vs $41 \cdot 6 \pm 4.4 \%)$ and $60 \mathrm{~h}$ $(40 \cdot 0 \pm 12 \cdot 1 \%$ vs $44.6 \pm 6.0 \%)$. During the 2 nd and 3 rd cycle, changes in serum oestradiol, FSH and $\mathrm{LH}$ similar to those in the 1 st cycle were observed.

After the suppression of basal FSH and LH concentrations all women displayed an LH surge. The first value that exceeded $180 \%$ of the mean value of the previous 4 samples was taken to indicate that the surge had started and the time of the previous sample was considered to be the 


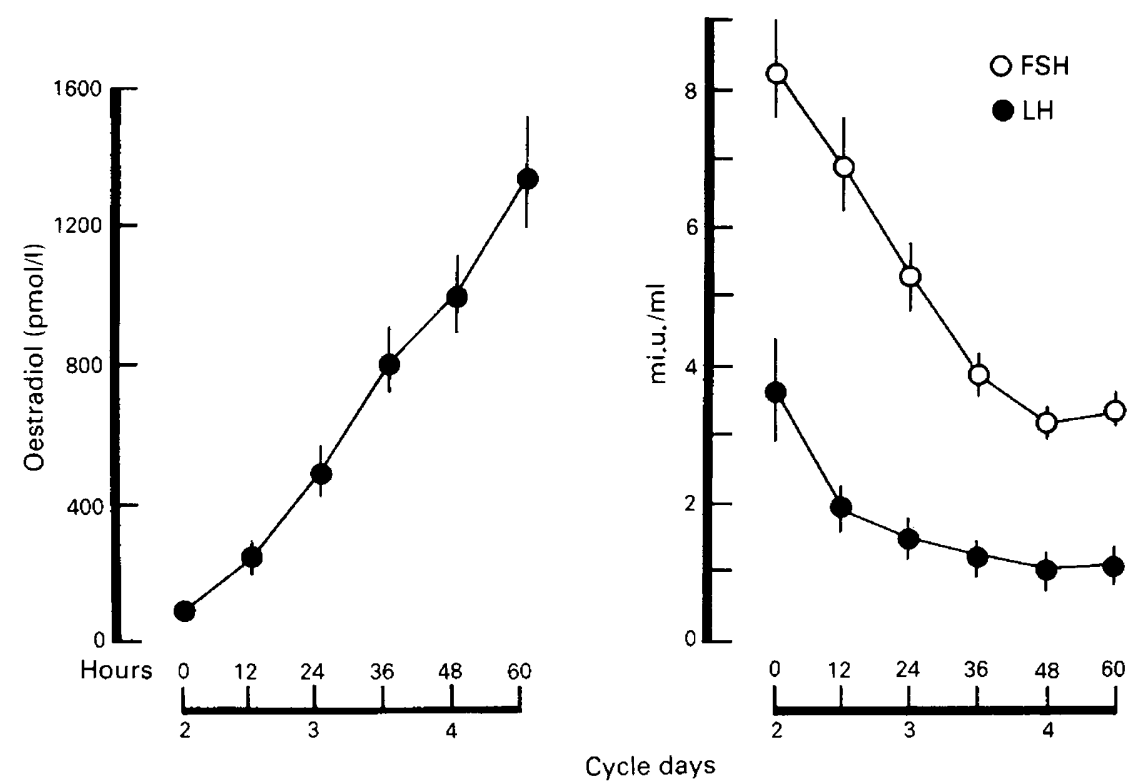

Fig. 1. Mean ( \pm s.e.m.) oestradiol, FSH and LH concentrations in the early follicular phase of the menstrual cycle during treatment of 8 normally cyclic women with intramuscular injections of oestradiol benzoate.

time of onset of the surge (Messinis et al., 1985). The mean ( \pm s.e.m.) time interval from the first oestradiol benzoate injection on the onset of the LH surge was significantly shorter in the 2nd $(62.2 \pm 1.0 \mathrm{~h}, P<0.01)$ and $3 \mathrm{rd}(63.4 \pm 1.1 \mathrm{~h}, P<0.05)$ cycles than in the 1st cycle $(68.2 \pm 1.0 \mathrm{~h})$, with no significant difference between the 2 nd and 3 rd cycle.

Figure 2 shows serum oestradiol, progesterone, $\mathrm{FSH}$ and $\mathrm{LH}$ concentrations before and during the LH surge in the 3 groups of cycles. Time 0 is the onset of the LH surge.

\section{Oestradiol}

The pattern of oestradiol concentrations was similar in all 3 experiments: values increased significantly during the $30 \mathrm{~h}$ before the onset of the $\mathrm{LH}$ surge to a peak at the onset of the surge in the 1 st $(1497 \pm 142 \mathrm{pmol} / 1)$ and $3 \mathrm{rd}$ cycle $(1557 \pm 195 \mathrm{pmol} / \mathrm{l})$ and $6 \mathrm{~h}$ after the onset of the surge in the 2 nd cycle $(1583 \pm 117 \mathrm{pmol} / 1)$, with no significant difference among the 3 groups of cycles. Then, oestradiol concentrations decreased dramatically during the LH surge in all 3 groups of cycles, reaching low levels at $66 \mathrm{~h}$. The decrease in the oestradiol concentrations is temporally related to the termination of exogenous oestradiol administration. This pattern of oestradiol change before and during the LH surge is similar to that seen before and during the midcycle LH surge of spontaneous cycles in women (Messinis \& Templeton, 1988a).

\section{Progesterone}

Mean ( \pm s.e.m.) serum progesterone concentrations in the 1 st cycle were low $(<2.0 \mathrm{nmol} / 1)$, with no significant changes throughout the experiment (Fig. 2). In the 2nd and 3rd cycle, progesterone values were also low before the onset of the LH surge, but, due to the exogenous administration of progesterone, concentrations increased significantly during the LH surge, reaching the level of $6.7 \pm 0.8$ and $22.3 \pm 3.2 \mathrm{nmol} / 1$ respectively $60 \mathrm{~h}$ after the onset of the surge $(P<0.001)$. At the time of onset of the LH surge (time 0 ), serum progesterone values were similar in the 2nd $(2 \cdot 2 \pm 0 \cdot 3 \mathrm{nmol} / \mathrm{l})$ and $3 \mathrm{rd}(2 \cdot 3 \pm 0 \cdot 3 \mathrm{nmol} / \mathrm{l})$ cycle and significantly higher than in the 1 st cycle 


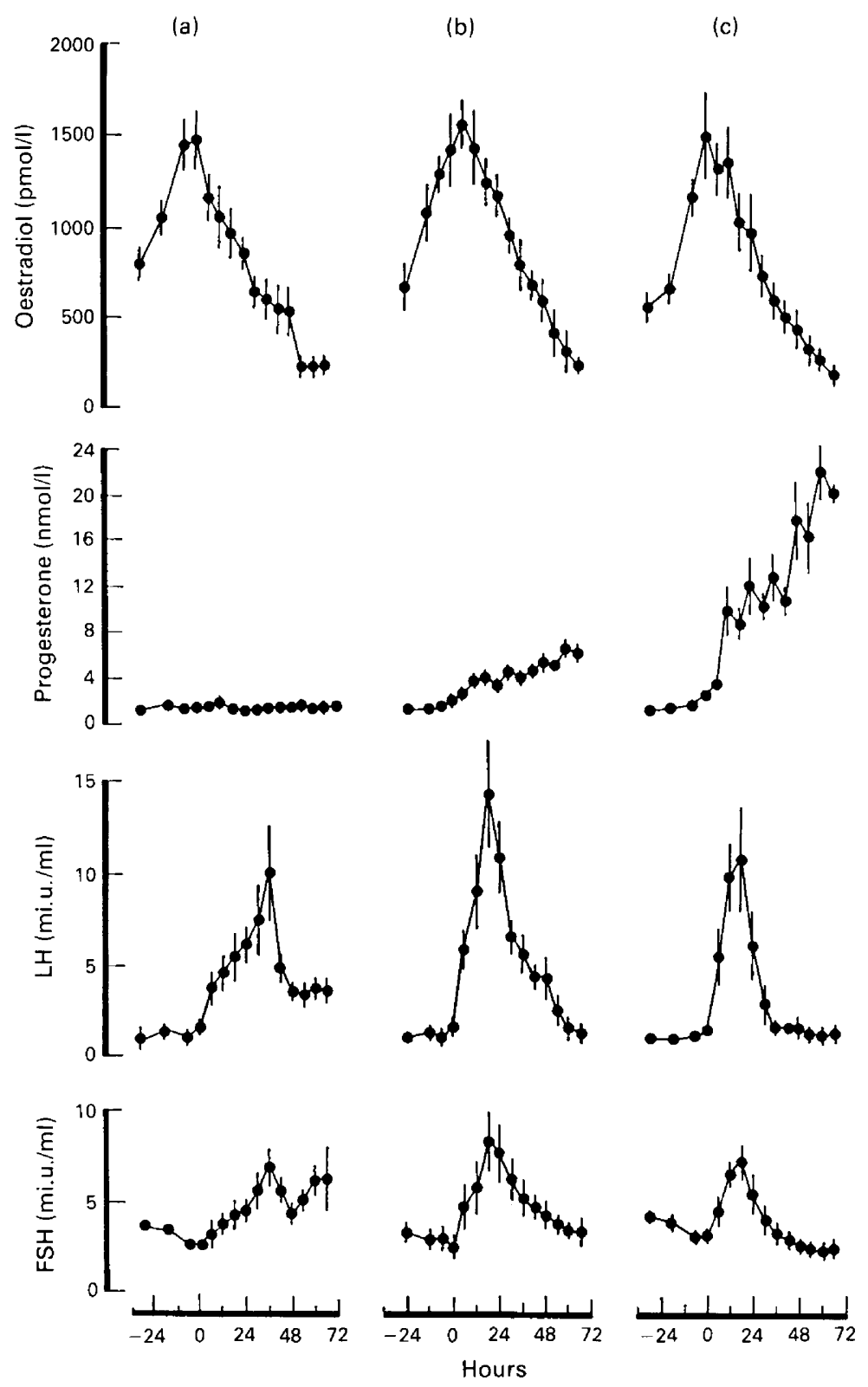

Fig. 2. Mean ( \pm s.e.m.) oestradiol, progesterone, LH and FSH concentrations before and during the LH surge induced in 8 normal women by the exogenous administration of oestradiol benzoate (a), oestradiol benzoate and low-dose progesterone (b) and oestradiol benzoate and high-dose progesterone (c) in the early follicular phase of the menstrual cycle. The data were normalized to the time of onset of the LH surge (time 0 ).

$(1.6 \pm 0.1 \mathrm{nmol} / 1, P<0.05)$. The pattern of progesterone concentrations in the 2 nd experiment was similar to that seen before and during the LH surge of spontaneous cycles (Messinis \& Templeton, 1987). In the 3rd cycle, serum progesterone values increased more rapidly and were significantly higher than in the 2 nd cycle from $12 \mathrm{~h}$ after the onset of the LH surge $(P<0.01)$. The 
pattern of progesterone changes in the 3rd cycle was similar to that in cycles of superovulated women (Messinis et al., 1985).

\section{LH}

The characteristics of the LH surge were different in the 3 groups of cycles (Fig. 2). LH concentrations at time 0 did not differ significantly among the 3 groups of cycles. During the 1 st cycle, serum LH values increased gradually and peaked $(9 \cdot 8 \pm 2.4 \mathrm{mi} . \mathrm{u} . / \mathrm{ml})$ at $36 \mathrm{~h}$. Then concentrations decreased rapidly at $48 \mathrm{~h}$ and remained stable thereafter up to $66 \mathrm{~h}(3.8 \pm 0.4 \mathrm{mi} . \mathrm{u} . / \mathrm{ml})$. At that point, LH concentrations were still significantly higher than the presurge levels at time 0 $(1.5 \pm 0.3 \mathrm{mi} . \mathrm{u} . / \mathrm{ml})(P<0.01)$, but did not differ significantly from the pretreatment basal LH values on cycle Day 2 . The ascending limb of the LH surge lasted for $31.5 \pm 1.8 \mathrm{~h}$ and the descending limb for $14.2 \pm 1.9 \mathrm{~h}$ (mean \pm s.e.m.). The mean ( \pm s.e.m.) duration of the LH surge was $45 \cdot 7 \pm 2 \cdot 2 \mathrm{~h}$ and the mean ( \pm s.e.m.) LH peak value $11 \cdot 3 \pm 2 \cdot 1 \mathrm{mi} . \mathrm{u} . / \mathrm{ml}$.

During the 2 nd cycle (low-dose progesterone), the LH surge was augmented. Serum LH values increased rapidly to a peak of $13.8 \pm 2.5 \mathrm{mi} . \mathrm{u} . / \mathrm{ml}$ at $18 \mathrm{~h}$. The ascending limb was significantly shorter $(21.0 \pm 1.5 \mathrm{~h})$ and the descending limb significantly longer $(34.5 \pm 2.1 \mathrm{~h})$ than in the $1 \mathrm{st}$ cycle $(P<0.01)$. The duration of the LH surge (mean \pm s.e.m.) was significantly longer (55.5 $\pm 2.1 \mathrm{~h}, P<0.01)$ and the LH peak value higher, although not significantly, than in the 1 st cycle. However, when LH peak value was considered as the mean of the 3 highest $\mathrm{LH}$ values in each individual surge, a significant difference was found between the 2 nd $(11.8 \pm 1.8 \mathrm{mi} . \mathrm{u} . / \mathrm{ml})$ and $1 \mathrm{st}$ cycle $(8.3 \pm 1.5 \mathrm{mi} . \mathrm{u} . / \mathrm{ml}, P<0.05)$.

During the 3 rd cycle (high-dose progesterone), the pattern of the LH surge was similar to that in the 2nd cycle, although of a smaller amplitude. LH concentrations increased to a peak of $10.8 \pm 2.9 \mathrm{mi} . \mathrm{u} . / \mathrm{ml}$ at $18 \mathrm{~h}$. The duration of the surge $(36.0 \pm 2.2 \mathrm{~h})$ was significantly shorter than in the other 2 cycles $(P<0.01)$. In contrast to the 1 st cycle, in the 2 nd and 3 rd cycles serum LH concentrations after the end of the LH surge remained low despite the decreasing oestradiol values.

\section{FSH}

In all experiments an FSH surge occurred simultaneously with the LH surge (Fig. 2). In each group of cycles the pattern of the FSH surge was similar to that of the LH surge. In the 2nd cycle the FSH surge was augmented, while in the $3 \mathrm{rd}$ cycle the duration decreased significantly. FSH concentrations at time 0 did not differ significantly among the 3 groups of cycles. Like the LH values in the 2 nd and 3rd cycle FSH concentrations after the end of the surge remained low until the end of the experiment, while in the 1st cycle they did not return to the presurge values and, $48 \mathrm{~h}$ after the onset of the surge, started to increase again.

In all cycles follicle size as assessed by ultrasound was $<8 \mathrm{~mm}$ in diameter throughout the experiment. All women had a menstrual-like bleeding 2-3 days after the end of each experiment. In 18 of the 23 cycles daily blood samples for LH measurement were taken from the women starting 8 days after the end of each experiment. A spontaneous LH surge occurred in these cycles $13 \cdot 2 \pm 0 \cdot 6$ days after the end of the experiment. At least one LH value of the midcycle LH surge was available in each cycle. The mean ( \pm s.e.m.) of these $\mathrm{LH}$ values $(28.5 \pm 5.8 \mathrm{mi} . \mathrm{u} . / \mathrm{ml})$ was significantly higher than the peak $\mathrm{LH}$ values in the present experiments $(P<0.001)$. All women menstruated $12-16$ days after the spontaneous $\mathrm{LH}$ surge.

\section{Discussion}

The present study confirms previous results concerning the suppressing effect of exogenous oestrogen on pituitary gonadotrophin secretion (Tsai \& Yen, 1971; Monroe et al., 1972; Young \& Jaffe, 
1976) and suggests that, during the early follicular phase of the human menstrual cycle, oestradiol is the mediator of the negative feedback effect of the ovaries on both FSH and LH secretion. Recent data have suggested that the differential control of FSH and LH secretion by the ovaries starts from the mid-follicular phase of the cycle (Messinis \& Templeton, 1988b).

This study clearly shows that a pattern of oestradiol values in blood similar to that seen before and during the midcycle $\mathrm{LH}$ surge of spontaneous cycles stimulates in the early follicular phase of the cycle both an LH and an FSH surge whose characteristics are different from those seen in spontaneous cycles (Hoff et al., 1983; Messinis \& Templeton, 1988a). Previous studies in the early follicular phase have failed to demonstrate an FSH surge and to characterize the oestrogen-induced LH surge and this is possibly due to different methodology, such as less frequent sampling (Tsai \& Yen, 1971; Young \& Jaffe, 1976; Chang \& Jaffe, 1978).

It is clear from the present results that exogenous progesterone is able to advance the onset of the gonadotrophin surge induced by exogenous oestradiol during the early follicular phase of the cycle, and modulate its characteristics. Progesterone stimulated an abrupt onset of the surge and changed the pattern into that seen at midcycle, i.e. with a shorter ascending and a longer descending limb (Hoff et al., 1983; Messinis \& Templeton 1988a). Previous data have also shown that LH concentrations increased more rapidly and reached an earlier peak when progesterone was injected in oestrogen-primed women as compared to when only oestradiol was given, but characteristics of the complete surge in that study were not reported (Chang \& Jaffe, 1978).

Although the described effect of exogenous progesterone on the pattern of the oestradiolinduced gonadotrophin surge is independent of the dose, the present study shows that the effect of progesterone on the amplitude and duration of the surge is dependent on the circulating concentrations of this steroid. When serum progesterone concentrations similar to those seen during the LH surge of spontaneous cycles were achieved, the oestradiol-induced surge of both LH and FSH was augmented, while in the presence of supraphysiological levels of progesterone the amplitude of the surge decreased and the duration shortened significantly.

An explanation of these results is difficult. However, the fact that during low-dose progesterone, but not oestrogen-only treatment, gonadotrophin concentrations after the end of the surge were suppressed to the presurge values demonstrates that, during the oestradiol-induced LH surge, progesterone exerts an inhibitory as well as a stimulatory effect on gonadotrophin secretion. This was particularly evident in the cycles treated with high-dose progesterone. Although the present study does not establish a clear-cut relationship between serum progesterone and gonadotrophin concentrations during the LH surge, it is evident that the final dimension of the oestradiol-induced gonadotrophin surge is subject to a balance between the stimulatory and the inhibitory effect of progesterone. It is suggested that above a certain concentration of progesterone the inhibitory effect dominates and the surge is diminished. Although these experiments were performed in the early follicular phase of the cycle, it is possible that similar events also take place at midcycle when progesterone modulates the gonadotrophin surge induced by the preovulatory oestradiol rise. The reduced amplitude of the oestradiol-induced gonadotrophin surge in the early follicular phase as compared to midcycle suggests that the pituitary reserves at that stage of the cycle are deficient.

The different patterns of serum progesterone values in the 3 groups of cycles and the arrested folliculogenesis in each experiment exclude the possibility that in the present study progesterone concentrations increased during the $\mathrm{LH}$ surge as a result of follicle luteinization. Also, the possibility that the observed differences in the characteristics of the LH surge among the 3 groups of cycles were due to the frequency of blood sampling is unlikely because there was a similar pattern of LH change in all women of each group. This possibility is further minimized by the fact that the women were used as their own controls.

In women superovulated for in-vitro fertilization the endogenous LH surge is markedly attenuated both in amplitude and duration (Messinis et al., 1985; Messinis \& Templeton, 1986) and this seems to be related to a non-steroidal substance secreted by the hyperstimulated ovaries (Messinis et al., 1986; Messinis \& Templeton, 1989). The present study, however, provides another 
possible mechanism of this attenuation in the cycles in which serum progesterone concentrations are supraphysiological.

In conclusion, the present study demonstrates that progesterone modulates the characteristics of the oestradiol-induced LH and FSH surges in the early follicular phase of the cycle by a dual effect. It is suggested that the dimension of the gonadotrophin surge is the result of a balance between a stimulatory and an inhibitory effect of progesterone on pituitary gonadotrophin secretion. Supraphysiological concentrations of progesterone result in a marked decrease of the duration of the surge and this is possibly part of the mechanism which attenuates the endogenous LH surge in superovulated women.

We thank Mr R. Duncan and the staff of the Reproductive Laboratories for the hormone assays: and Sister Linda Thomson, whose post was funded by Serono Laboratories (UK), for help in managing the patients.

\section{References}

Chang, R.J. \& Jaffe, R.B. (1978) Progesterone effects on gonadotropin release in women pretreated with estradiol. J. clin. Endocr. Metab. 47, 119-125.

Hoff, J.D., Quigley, M.E. \& Yen, S.S.C. (1983) Hormonal dynamics at midcycle: a reevaluation. $J$. clin. Endocr. Metab. 57, 792-296.

Leyendecker, G., Wardlaw, S. \& Nocke, W. (1972) Experimental studies on the endocrine regulations during the periovulatory phase of the human menstrual cycle. Acta endocr., Copenh. 71, 160-178.

Liu, J.H. \& Yen, S.S.C. (1983) Induction of midcycle gonadotropin surge by ovarian steroids in women: a critical evaluation. $J$. clin. Endocr. Metab. 57, $797-802$.

Liu, J.H., Garzo, G., Morris, S., Stuenkel, C., Ulman, A. \& Yen, S.S.C. (1987) Disruption of follicular maturation and delay of ovulation after administration of the antiprogesterone RU 486. J. clin. Endocr. Metab. 65, 1135-1140.

March, C.M., Goebelsmann, U., Nakamura, R.M. \& Mishell, D.R., Jr (1979) Roles of oestradiol and progesterone in eliciting the midcycle luteinizing hormone and follicle-stimulating hormone surges. $J$. clin. Endocr. Metab. 49, 507-513.

Messinis, I.E. \& Templeton, A. (1986) The effect of pulsatile follicle stimulating hormone on the endogenous luteinizing hormone surge in women. Clin. Endocrinol. 25, 633-640.

Messinis, I.E. \& Templeton, A. (1987) Effect of high dose exogenous oestrogen on midcycle luteinizing hormone surge in human spontaneous cycles. Clin. Endocrinol. 27, 453-459.

Messinis, I.E. \& Templeton, A.A. (1988a) The endocrine consequences of multiple folliculogenesis. J. Reprod. Fert., Suppl. 36, 27-37.

Messinis, I.E. \& Templeton, A. (1988b) Blockage of the positive feedback effect of oestradiol during prolonged administration of clomiphene citrate to normal women. Clin. Endocrinol. 29, 509-516.

Messinis, I.E. \& Templeton, A.A. (1989) Pituitary response to exogenous LHRH in superovulated women. J. Reprod. Fert. 87, 633-639.
Messinis, I.E., Templeton, A. \& Baird, D.T. (1985) Endogenous luteinizing hormone surge during superovulation induction with sequential use of clomiphene citrate and pulsatile human menopausal gonadotropin. J. clin. Endocr. Metab. 61, 1076-1080.

Messinis, I.E., Templeton, A. \& Baird, D.T. (1986) Relationships between the characteristics of endogenous luteinizing hormone surge and the degree of ovarian hyperstimulation during superovulation induction in women. Clin. Endocrinol. 25, 393-400.

Monroe, S.E., Jaffe, R.B. \& Midgley, A.R., Jr (1972) Regulation of human gonadotropins. XII. Increase in serum gonadotropins in response to estradiol. $J$. clin. Endocr. Metab. 34, 342-347.

Rattle, S.J., Purnell, D.R., Williams, P., Siddle, K. \& Forrest, G.C. (1984) New separation method for monoclonal immunoradiometric assays and its application to assays for thyrotropin and human choriogonadotropin. Clin. Chem. 30, 1457-1462.

Soos, M. \& Siddle, K. (1983) Characterization of monoclonal antibodies for human luteinizing hormone and mapping of antigenic determinants on the hormone. Clin. Chem. Acta 133, 263-274.

Tsai, C.C. \& Yen, S.S.C. (1971) The effect of ethinylestradiol administration during the early follicular phase of the cycle on the gonadotropin levels and ovarian function. J. clin. Endocr. Metab. 33, 917-923.

Yen, S.S.C. \& Lein, A. (1976) The apparent paradox of the negative and positive feedback control system on gonadotropin secretion. Am.J. Obstet. Gynecol. 126, 942-954.

Yen, S.S.C. \& Tsai, C.C. (1972) Acute-gonadotropin release induced by exogenous estradiol during the mid-follicular phase of the menstrual cycle. J. clin. Endocr. Metab. 34, 298-305.

Young, J.R. \& Jaffe, R.B. (1976) Strength-duration characteristics of estrogen effects of gonadotropin response to gonadotropin-releasing hormone in women. II. Effects of varying concentrations of estradiol. J. clin. Endocr. Metab. 42, 432-442.

Received 26 May 1989 